\title{
Biological efficiency of plant protection products to control codling moth on apple immune cultivars
}

\author{
Natalia Kashirskaya, Andrei Kuzin*, and Anna Kochkina \\ I.V. Michurin Federal Scientific Centre, 30 str. Michurina, Micurinsk, 393774, Russia
}

\begin{abstract}
The caterpillars of this codling moth can damage up to $90 \%$ of fruits during mass reproduction. Changing weather conditions contribute to increasing the harmfulness of the primary pest of the apple tree. The research was carried out to select modern plant protection products with high biological efficiency to control codling moths and increase the productivity of the apple orchard. The research was carried out in the I.V. Michurin Federal Scientific Centre apple orchard. We studied the efficiency of plant protection products on apple cultivars immune to scab: 'Akademik Kazakov,' 'Vympel,' 'Bylina,' 'Rozhdestvenskoye,' 'Fregat.' The efficiency of these preparations was studied with low application rates to reduce the fruit damages by codling moth. The values of fruit damage in control without treatment during the years of the research as the result of vital pest activity: Generation 1: 4.9-17.8\%; Generation 2: 5.4-16.3\%. In the experiment treatment, Generation 1 damaged $0.24-1.50 \%$, and Generation 2 injured $0.36-1.60 \%$ of fruits. The biological efficiency of the experimental treatment was high and reached controlling Generation 1: $91.0-98.5 \%$, Generation 2: $90.0-96.0 \%$. The average yield in the experimental treatment was $29.4 \mathrm{~kg}^{-1} \mathrm{e}^{-1}$ with a share of first-grade fruits $85-90 \%$ (2019) and $39.4 \mathrm{~kg}^{-1} \mathrm{tre}^{-1}, 90-91 \%(2020)$.
\end{abstract}

Codling moth Cydia pomonella (L.) (Lepidoptera: Tortricidae) - one of the most dangerous apple pest which can cause significant economic damage by reducing the commercial value of fruits and yield $[1,2]$. Pest caterpillars in different years can damage up to $70-90 \%$ of fruits of all pome and many stone fruits and walnut in all regions of their cultivating [3].

The pest has several generations in apple orchards, which harmfulness is determined by climatic conditions [4]. For example, in Central Russia, there are two generations of codling moths every year.

One of the most reasons for the pest harmfulness increase is global climate change. These processes lead to the spread of pest populations: their survival and fertility are increasing, conditions for migrations and expansions of habitats are improving $[6,7]$.

With the expansion in the reproduction of pests, the amount of chemical plant protection products also enhances. However, it leads to an increase in the pesticide load on the

${ }^{*}$ Corresponding author: andrey.kuzin1967@yandex.ru 
agrocenosis. Thus, the new environment and economic challenges arise because of pest resistance to these products and a negative impact on the environment $[8,9]$.

It is necessary to monitor the number of codling moths to control pest development. On this basis, a short-term forecast of harmfulness for reasonability of modern plant protection product application must be developed, which has high biological efficiency [10].

The application of new products with the shortest waiting time and low ecological toxicity decreases the load of insecticides on the orchard $[1,11,12]$.

The selection of modern plant protection products with high biological efficiency against codling moth is today an essential problem for increasing apple orchard productivity.

The research was done in the apple orchard of I.V. Michurin Federal Scientific Centre in 2019-2020 (planted in 2015, grafted on rootstock B118, immune to scab cultivars 'Akademik Kazakov,' 'Vympel,' 'Bylina,' 'Rozhdestvenskoye,' 'Fregat,' planting pattern $6.0 \times 4.0 \mathrm{~m}-417$ tr. ha ${ }^{-1}$. Experiment design: Control (without treatments), experimental plant protection system (EPPS): Atabron, SC $\left(0.71 \mathrm{ha}^{-1}\right)$; Coragen, SC (0.2 $\left.1 \mathrm{ha}^{-1}\right)$; Calypso, SC $\left(0,41 \mathrm{ha}^{-1}\right)$; Avaunt, SC (0.35 $\left.1 \mathrm{ha}^{-1}\right)$; conventional plant protection system (CPPS): Theja, SC(0.4 $\left.1 \mathrm{ha}^{-1}\right)$; Kinfos Neo, EC (0.5 $\left.1 \mathrm{ha}^{-1}\right)$; Danadim Expert, EC (1.5 $\left.1 \mathrm{ha}^{-1}\right)$; Pyrinex Super, EC $\left(1.01 \mathrm{ha}^{-1}\right)$. The area of each PPS application was 2 ha. Fruit damages were evaluated after Generation 1 and 2 separately. Commercial fruit grade was determined according to the Russian Standard (GOST RF) 34314-2017.

The basis for decision making about separate protection sprayings and plant protection product choosing was the number of butterflies in pheromone traps and the sum of the effective temperature on a corresponding day. The research was carried out according to the methods well adopted to evaluate the efficiency of pest control. Statistical analyzes of obtained data were done according to Fisher's method. We calculated the value of the lowest significant difference (LSD) among the study treatments at $\mathrm{P}<0.05$. We considered the differences greater than calculated LSD as significant.

The weather during the research had considerable differences compare to the values, which were average for our region in the last 50 years. At the end of the spring - at the beginning of summer 2019 , the average day temperature was $2.4-3.5^{\circ} \mathrm{C}$, more than usual. On the other hand, the rainfall (in May was more on $15.0 \mathrm{~mm}$ and in June $40.6 \mathrm{~mm}$ less) was not as expected. The temperature was on the average multiyear level in other summer months (July, August). Still, the rainfall considerably varied regarding the climate norm (in July, it was 16\% more and in August 34\% less).

The differences with climate norm were not significant in Mai $2020\left( \pm 1,9^{\circ} \mathrm{C}\right)$. But the rainfall in this Month was $42 \%$ more than usual. The amount of precipitation in June was even more (up to $75 \%$ more than usual). The temperature did not differ significantly from the multi-year average in July and August. July 2020, especially towards the end of the Month, was very dry, and the amount of precipitation was $52 \%$ less than usual. Later, in August, the drought intensified because precipitation was $78 \%$ less than the climatic norm.

The threshold value for the development of the apple moth is the temperature more than $+10^{\circ} \mathrm{C}$ (effective temperature). When the sum of the effective temperatures (SET) reaches $550-600^{\circ} \mathrm{C}$, the conditions for the development of the second generation are good. When SET is more than $900^{\circ} \mathrm{C}$, it means the mass expansion of the pest. In 2019 , this value was $879.7^{\circ} \mathrm{C}$, and in the subsequent $2020-731.1^{\circ} \mathrm{C}$ (Table 1).

Table 1. Accumulation of the effective temperature sum, ${ }^{\circ} \mathrm{C}$

\begin{tabular}{|c|c|c|c|c|}
\hline \multirow{2}{*}{ Years } & \multicolumn{4}{|c|}{ Months } \\
\cline { 2 - 5 } & May & June & July & August \\
\hline 2019 & 276.1 & 620.7 & 879.7 & 1129.6 \\
\hline 2020 & 103.1 & 397.5 & 731.1 & 1001.3 \\
\hline
\end{tabular}


To effectively control the pest development in generation 2 , it is necessary to create forecasts and possible scenarios. Therefore, the SET value is used to determine the timing of the ontogenesis stages of the codling moth.

The threshold level in such a forecast is the SET value of $500^{\circ} \mathrm{C}$. After the SET reaches this level, it is possible to create a scenario with the expected development of caterpillars in 2-3 weeks.

The $500{ }^{\circ} \mathrm{C}$ SET was in the second decade of June 2019. Therefore, the development of Generation 2 could be expected at the level of $80-90 \%$. The $500{ }^{\circ} \mathrm{C}$ SET three weeks later in the following year, at the end of the first decade July. Therefore, the expected development of Generation 2 could be $35-55 \%$. When the SET reaches $610{ }^{\circ} \mathrm{C}$, Generation 2 of butterflies appears after ten days, and the flight of codling moth butterflies could continue from the mid of July till the middle of August [13].

After overwintering, Generation 1 codling moth butterflies' flight began in the early second ten-day period of May (2019) and ten days later in 2020. We observed the main number of Generation 1 butterflies from May 10 to 20 (2019) and from May 20 to May 30 (2020). The highest activity of Generation 2 was from July 1 to July 10 (2019) and in 2020 ten days later - from July 10 to July 20.

The level of fruit damages in control significantly varied by different cultivars. The number of damaged fruits by Generation 1 was in the frame 5.1-17.1\%, by Generation 2: 5.4-16.3\%. But in 2020, these variations were not so considerable by Generation 1: 4.9$7.6 \%$. The most cultivar difference in fruit infestation was in Generation 2 (15.8-25.8\%) in 2020.

The different susceptibility to codling moth damages depending on scab resistance is well described in the literature - codling moth less injured the scab resistant cultivars [14].

The values of fruit damages due to codling moth in gross yield in EPPS (Generation 1: 0.24-1.5\%; Generation 2: $0.36-1.60 \%$ ) confirm the high efficiency of this treatment. On the other hand, the fruit damage value in the CPPS treatment was higher: $0.55-2.30 \%$ (Generation 1) and 0.70-2.20 (Generation 2).

The biological efficiency of EPPS during the years of study was the highest and reached controlling the Generation 1: 91.0-98.5\%, Generation 2: 90.0-96.0 \% (Table 2). The CPPS efficiency was 85.3-96.3 (Generation 1) and 83.0-92.0\% (Generation 2).

Table 2. Biological efficiency of plant protection products to control codling moth

\begin{tabular}{|c|c|c|c|c|}
\hline Treatment & \multicolumn{2}{|c|}{2019} & \multicolumn{2}{|c|}{2020} \\
\hline & Generation 1 & Generation 2 & Generation 1 & Generation 2 \\
\hline \multicolumn{5}{|c|}{ 'Akademik Kazakov' } \\
\hline EPPS & 91.0 & 93.9 & 91.7 & 92.9 \\
\hline CPPS & 87.1 & 90.2 & 85.7 & 86.2 \\
\hline \multicolumn{5}{|c|}{ 'Vympel' } \\
\hline EPPS & 93.8 & 90.0 & 94.0 & 94.9 \\
\hline CPPS & 89.2 & 87.0 & 87.4 & 88.4 \\
\hline \multicolumn{5}{|c|}{ 'Bylina' } \\
\hline EPPS & 90.2 & 91.0 & 92.0 & 96.0 \\
\hline CPPS & 86.2 & 85.8 & 85.3 & 87.9 \\
\hline \multicolumn{5}{|c|}{ 'Rozhdestvenskoye' } \\
\hline EPPS & 93.2 & 92.1 & 95.0 & 93.0 \\
\hline CPPS & 90.0 & 89.5 & 88.9 & 83.2 \\
\hline \multicolumn{5}{|c|}{ 'Fregat' } \\
\hline EPPS & 98.5 & 93.0 & 93.0 & 93.7 \\
\hline CPPS & 96.3 & 87.3 & 86.0 & 86.0 \\
\hline
\end{tabular}


The average yield in the EPPS treatment was from $20.5 \mathrm{~kg} \mathrm{tr}^{-1}$ to $29.4 \mathrm{~kg} \mathrm{tr.}^{-1}$, the share of fruits of the highest commercial grade was 86-89\% (2019). In 2020, the average yield in EPPS treatment was from $21.9 \mathrm{~kg} \mathrm{tr} .^{-1}$ to $39.4 \mathrm{~kg} \mathrm{tr} .^{-1}$, the percentage of fruits of the highest commercial quality was $89-90 \%$ (2020). In CPPS treatment average yield was $20.0-28.7 \mathrm{~kg}$ tr. $^{-1}$ (highest grade share 80-85 \%) (2019) and in 2020, yield was 22.0-38.5 kg tr. ${ }^{-1}$ (highest grade share $79-83 \%$ ) (Table 3 ). The application of sustainable plant protection system provides high yield and high efficiency controlling the codling moth development) depending on the cultivar.

Table 3. Impact of treatments on yield and apple fruit quality

\begin{tabular}{|c|c|c|c|c|c|c|c|c|c|c|}
\hline \multirow[t]{2}{*}{ Вариант } & \multicolumn{5}{|c|}{2019} & \multicolumn{5}{|c|}{2020} \\
\hline & $\begin{array}{l}\text { Yield, } \\
\mathrm{kg} / \mathrm{tr}^{\mathrm{i}}{ }^{1}\end{array}$ & $\begin{array}{l}\text { Highest } \\
\text { grade }\end{array}$ & \begin{tabular}{|l|} 
First \\
grade
\end{tabular} & \begin{tabular}{|l}
$\begin{array}{l}\text { Second } \\
\text { grade }\end{array}$ \\
\end{tabular} & $\begin{array}{l}\text { Non- } \\
\text { standard }\end{array}$ & $\begin{array}{l}\text { Yield, } \\
\text { kg/tr. }{ }^{\text {il }}\end{array}$ & $\begin{array}{l}\text { Highest } \\
\text { grade }\end{array}$ & \begin{tabular}{|l|} 
First \\
grade
\end{tabular} & \begin{tabular}{|l|}
$\begin{array}{l}\text { Second } \\
\text { grade }\end{array}$ \\
\end{tabular} & $\begin{array}{l}\text { Non- } \\
\text { standard }\end{array}$ \\
\hline \multicolumn{11}{|c|}{ 'Akademik Kazakov' } \\
\hline Control & 25.3 & 0 & 0 & 0 & 100.0 & 27.0 & 0 & 0 & 0 & 100.0 \\
\hline EPPS & 27.8 & 89.0 & 6.0 & 3.0 & 2.0 & 29.5 & 90.0 & 7.0 & 2.0 & 1.0 \\
\hline CPPS & 26.5 & 85.0 & 5.0 & 7.0 & 3.0 & 29.0 & 82.0 & 8.0 & 7.0 & 3.0 \\
\hline $\mathbf{L S D}_{05}$ & 0.6 & & & & & 1.1 & & & & \\
\hline \multicolumn{11}{|c|}{ 'Vympel' } \\
\hline Control & 24.1 & 0 & 0 & 0 & 100.0 & 32.3 & 0 & 0 & 0 & 100.0 \\
\hline EPPS & 29.4 & 86.0 & 7.0 & 4.0 & 3.0 & 39.4 & 89.0 & 6.0 & 4.0 & 1.0 \\
\hline CPPS & 28.7 & 80.0 & 6.0 & 10.0 & 4.0 & 38.5 & 83.0 & 5.0 & 10.0 & 2.0 \\
\hline $\mathbf{L S D}_{05}$ & 0.7 & & & & & 1.1 & & & & \\
\hline \multicolumn{11}{|c|}{ 'Bylina' } \\
\hline Control & 19.5 & 0 & 0 & 0 & 100.0 & 25.0 & 0 & 0 & 0 & 100.0 \\
\hline EPPS & 23.6 & 87.0 & 8 & 3.0 & 2.0 & 28.7 & 90.0 & 7.0 & 2.0 & 1.0 \\
\hline CPPS & 23.0 & 81.0 & 7.0 & 9.0 & 3.0 & 29.0 & 82.0 & 9.0 & 7.0 & 2.0 \\
\hline LSD $_{05}$ & 2.2 & & & & & 0.9 & & & & \\
\hline \multicolumn{11}{|c|}{ 'Rozhdestvenskoye' } \\
\hline Control & 17.1 & 0 & 0 & 0 & 100.0 & 18.2 & 0 & 0 & 0 & 100.0 \\
\hline EPPS & 20.5 & 87.0 & 7.0 & 5.0 & 1.0 & 21.9 & 89.0 & 6.0 & 4.0 & 1.0 \\
\hline CPPS & 20.0 & 83.0 & 5.0 & 9.0 & 3.0 & 22.0 & 79.0 & 5.0 & 14.0 & 2.0 \\
\hline $\mathbf{L S D}_{05}$ & 1.9 & & & & & 1.1 & & & & \\
\hline \multicolumn{11}{|c|}{ 'Fregat' } \\
\hline Control & 20.7 & 0 & 0 & 0 & 100.0 & 24.5 & 0 & 0 & 0 & 100.0 \\
\hline EPPS & 24.2 & 88.0 & 8.0 & 2.0 & 2.0 & 27.8 & 90.0 & 6.0 & 3.0 & 1.0 \\
\hline CPPS & 24.5 & 80.0 & 10.0 & 7.0 & 3.0 & 28.0 & 83.0 & 9.0 & 6.0 & 2.0 \\
\hline $\mathbf{L S D}_{05}$ & 1.4 & & & & & 0.9 & & & & \\
\hline
\end{tabular}

Thus, the results obtained in the conditions of 2019-2020 confirmed that the plant protection products in the experimental treatment had high biological efficiency and, at the same time, contributed to reducing the insecticide load of apple orchard. These factors stimulated high yielding and good fruit quality. The new generations' insecticides already demonstrated high efficiency in ecologized protection systems [16]. The application of new generations' insecticides (Atabron, Coragen, Calypso, Avaunt) provided high biological efficiency (90.0-98.5\%), controlling the first and second generations of codling moth by the good commercial value of fruits (80.0-90.0\% of premium quality). 


\section{References}

1. N.Ya. Kashirskaya, A.M. Kochkina, A.A. Skrylev, Pomiculture and small fruits culture in Russia, 59, 227-232 (2019) https://doi.org/10.31676/2073-4948-2019-59-227-232

2. T. Mahi, A. Harizia, A. Benguerai, T. Canelo, R. Bonal, Bull. Insect. 74(1), 139-146 (2021) http://www.bulletinofinsectology.org/pdfarticles/vol74-2021-139-146mahi.pdf

3. S. Kumar, L.G. Neven, H. Zhu, R.Zhang. J. Econ. Entomol., 108(4), 1708-1719 (2015) https://doi.org/10.1093/jee/tov166

4. S, Stoeckli, M. Hirschi, C. Spirig, P. Calanca, M.W. Rotach, J. Samietz, PLoS One, 7(4), e35723 (2012) https://doi.org/10.1371/journal.pone.0035723

5. R. Juszczak, L. Kuchar, J. Leśny, J. Olejnik, Int. J. Biometeorol., 57(1), 31-44 (2013) https://doi.org/10.1007/s00484-012-0531-0

6. V. Karuppaiah, G.K. Sujayanad, World J. Agric. Sci., 8(3), 240-246 (2012) https://www.researchgate.net/publication/332012685

7. J.R. Lamichhane, M. Barzman, K. Booij, P. Boonekamp, N. Desneux, L. Huber, P. Kudsk, S.R.H. Langrell, A. Ratnadass, P. Ricci, J.-L. Sarah, A. Messean, Agron. Sustain. Dev., 35, 443-459 (2015) https://doi.org/10.1007/s13593-014-0275-9

8. C. Bass, I. Denholm, M.S. Williamson, R. Nauen, Pestic. Biochem. Phys., 121, 78-87 (2015) https://doi.org/10.1016/j.pestbp.2015.04.004

9. K.G. Amarasekare, P.W. Shearer, N.J. Mills, Biol. Control., 102, 7-16 (2016) https://doi.org/10.1016/j.biocontrol.2015.10.015

10. A.M. Kochkina, N.Ya. Kashirskaya, Pomiculture and small fruits culture in Russia, 55, 255-258 (2018) https://doi.org/10.31676/2073-4948-2018-55-255-258

11. I.I. Temreshev, P.A. Esenbekova, A.O. Sagitoy, N.S. Mukhamadiev, G.B. Sarsenbaeva, A.V. Ageenko, J. Homziak, IJEAB, 3(1), 72-91 https://doi.org/10.22161/ijeab/3.1.10

12. A.K. Apazhev, A.G. Fiapshev, L.M. Hazhmetov, L.Z. Shekikhacheva, IOP Conf. Ser.: Earth Environ. Sci., 315(5), $052023 \quad$ (2019) https://doi.org/10.1088/1755$1315 / 315 / 5 / 052023$

13. M.K. Balaško, R. Bažok, K.M. Mikac, D. Lemic, I.P. Živković, Insects, 11(1), 38 (2020) https://doi.org/10.3390/insects11010038

14. W. Danelski, D. Kruczyńska, P. Bielicki, E. Rozpara, Turk. J. Agric. Forest., 41, 121126 (2017) https://doi.org/10.3906/tar-1612-76

15. A.Valiuškaitè, N. Uselis, D. Kviklys, J. Lanauskas, N. Rasiukevičiūtè, ZemdirbysteAgriculture, 104(4), 353-358 (2017) https://doi.org/10.13080/z-a.2017.104.045

16. Y.A. Mahmood, H.A. Salem, Sh.E.M. Shalaby, A.S. Addel-Razek, I.M.A. Ebadah, Int. J. Agric. Res., 9(4), 210-218 (2014) https://doi.org/10.3923/ijar.2014.210.218. 